In: ISMÉRIO, Clarisse (Org.). Patrimônio Cultural: simbolismos, intertextualidades e polifonias [livro eletrônico]. São Paulo: Vecher, 2021. Disponível em: <https://doi.org/10.47585/9786599324215>.

\title{
Teias e labirintos na reconstrução da memória institucional de um Campus do Instituto Federal do Rio de Janeiro: motivações e desafios iniciais
}

\author{
Monique Inocencio ${ }^{1}$ e Pedro Guedes ${ }^{2}$ \\ doi.org/10.47585/9786599324215.6
}

Com base nos pressupostos teóricos do campo da memória social, do conceito mais específico de memória institucional e de teóricos da relação entre educação, linguagem e memória, o que se pretende neste texto é discutir o processo em andamento de realização de um projeto de pesquisa intitulado Criação do acervo digital de história e memória do IFRJ Campus Duque de Caxias, cujo início formal se deu em julho do ano de 2020 e vem desde então sendo desenvolvido no Campus Duque de Caxias do Instituto Federal de Educação, Ciência e Tecnologia do Rio de Janeiro. O objetivo da iniciativa é a construção, em um ambiente virtual, de uma coletânea de fotos, vídeos, relatos e documentos que registrem o histórico de construção, fundação, inauguração, consolidação e funcionamento da instituição, que pertence à rede federal de ensino. Refletimos aqui sobre o quanto o resgate de memórias a que se propõe o acervo colabora para o universo conceitual e teórico da memória social e institucional ao recompor o labirinto mnemônico de um espaço acadêmico e propor formas e métodos de produção memorialística.

Palavras-chave: Memória institucional; Preservação cultural; Instituto Federal do Rio de Janeiro.

\footnotetext{
1 Professora de Língua Portuguesa e Literatura do Instituto Federal de Educação, Ciência e Tecnologia do Rio de Janeiro, Campus Duque de Caxias; Mestre em Letras (Teoria Literária) pela Universidade Federal do Rio de Janeiro, http://lattes.cnpq.br/8273017540812611, e-mail: monique.inocencio@ifrj.edu.br.

2 Estudante de ensino médio-técnico em Petróleo e Gás do Instituto Federal de Educação, Ciência e Tecnologia do Rio de Janeiro, Campus Duque de Caxias, http://lattes.cnpq.br/3548829897396623, e-mail: pepe02221@gmail.com.
} 


\section{Introdução}

O projeto de pesquisa Criação do acervo digital de história e memória do IFRJ Campus Duque de Caxias vem sendo desenvolvido por uma equipe composta pela docente autora e coordenadora do projeto e cinco estudantes: quatro deles de ensino médio integrado à educação técnica e profissional em Petróleo e Gás, um dos quais é bolsista PIBIC Jr., contemplado por um edital interno de fomento à pesquisa, e outras três alunas voluntárias de iniciação científica. Participa também, como aluno voluntário de iniciação científica, um estudante do curso técnico integrado ao ensino médio em Informática para Internet, que funciona no Campus Engenheiro Paulo de Frontin do IFRJ. Esse aluno vem colaborando com a parte técnica da formulação do ambiente virtual do acervo. O objetivo do empreendimento é a criação de um ambiente virtual, inserido no próprio site institucional do Instituto Federal de Educação, Ciência e Tecnologia do Rio de Janeiro, no qual seja reunida e disponibilizada a um público amplo e diversificado uma coletânea de arquivos textuais e imagéticos que narrem a trajetória de concepção, construção, inauguração, consolidação e funcionamento do Campus Duque de Caxias do instituto.

Considerando o potencial formativo e humanizador desse espaço acadêmico, nos parece relevante formalizar o registro de sua história, no intuito de tornar seu passado acessível ao tempo presente e construir redes e tessituras de memórias dos agentes que dele fazem e/ou fizeram parte, integrando, assim, a história da instituição de ensino com as narrativas particulares de diversos indivíduos que lá atuaram como alunos, docentes, técnicos-administrativos, comunidade externa e outros papéis sociais que possam estar atrelados à existência do Campus.

O referencial acadêmico que orienta e norteia o projeto guarda boa dose de pluralidade, mas está fincado, em grande medida, na discussão proposta por Maurice Halbwachs em sua obra $A$ memória coletiva, livro no qual o sociólogo aborda a memória sob duas perspectivas complementares: a memória individual e sua contraface à qual o pesquisador confere mais destaque; e a memória coletiva, construída a partir de redes de afeto que o indivíduo estabelece com os diversificados grupos sociais de que faz parte, e instância responsável pela manutenção de tradições e estabelecimento de elos entre os seres humanos. Para o autor francês:

\footnotetext{
nossas lembranças permanecem coletivas, e elas nos são lembradas pelos outros, mesmo que se trate de acontecimentos nos quais só nós estivemos envolvidos, e com objetos que só nós vimos. É porque, em realidade, nunca estamos sós. Não é necessário que outros homens estejam lá, que se distingam materialmente de nós: porque temos sempre conosco e em nós uma quantidade de pessoas que não se confundem. (HALBWACHS, 2003, p. 30).
}

Para o desdobramento do conceito específico de memória institucional, serve-nos de suporte a tese de doutorado de Icléia Thiesen, intitulada Memória institucional: a construção conceitual numa abordagem teórico-metodológica, trabalho no qual são elucidadas definições importantes e necessárias às empreitadas de registro de memória e construção de narrativas coletivas, especialmente aquelas que pretendem tecer e difundir a memória de instituições 
específicas, como é o caso da atividade da qual tratamos aqui. A respeito da relação entre essas terminologias e nossa pesquisa, é válido citar a seguinte síntese de Letícia Gorri Molina e Marta Lígia Pomim Valentim em artigo no qual as autoras escrevem sobre os conceitos de memória organizacional, memória corporativa e memória institucional:

A memória é considerada o único instrumento através do qual ideias e palavras podem ser reunidas, fugindo, assim, ao império do imediato: imprime as direções do tempo e permite uma continuidade social. Sem ela, desapareceriam os elos sociais, assim como a própria noção de sociedade, as identidades individuais e coletivas, a possibilidade da construção do conhecimento, ou seja, pode ser considerada uma ferramenta para a construção de uma determinada sociedade, assim como de transmissão cultural. (MOLINA e VALENTIM, 2011, p. 266).

Partindo desta necessária articulação entre rememoração, identidade e manutenção dos vínculos de afeto e pertencimento entre as pessoas que fazem parte de um mesmo grupo social ou, no caso mais restrito que debatemos aqui: da mesma instituição de ensino, seguimos motivados em nosso labiríntico percurso de (re)construção memorialística desse estabelecimento de educação localizado na Baixada Fluminense, no bairro de Vila Sarapuí, situado no primeiro distrito do município de Duque de Caxias, na Região Metropolitana do Rio de Janeiro.

O IFRJ CDUC foi inaugurado em setembro de 2006, ainda como Unidade Avançada do então Centro Federal de Educação Tecnológica de Química. Somente com a promulgação da Lei $n^{\circ}$ 11.892, de 29 de dezembro de 2008, que cria os institutos federais e sistematiza a Rede Federal de Educação Profissional, Científica e Tecnológica, e da portaria do Ministério da Educação no 4, de 6 de janeiro de 2009, que determina quais Campi comporão a estrutura de cada um dos institutos federais, o então CEFET Química se converte em Instituto Federal de Educação, Ciência e Tecnologia do Rio de Janeiro e a Unidade Avançada Duque de Caxias se transforma no Campus Duque de Caxias do IFRJ.

Ao longo desses anos de funcionamento, o Campus vem oferecendo educação profissionalizante a alunos de variados perfis socioeconômicos e múltiplas faixas etárias nos seus diferentes cursos, que atualmente são os seguintes: Curso Técnico em Petróleo e Gás; Curso Técnico em Plásticos (que durante alguns anos funcionou com outra nomenclatura: Curso Técnico em Polímeros), ambos ofertados nas variações integrado ao ensino médio e concomitante/subsequente ao ensino médio ${ }^{3}$; Curso Técnico em Química, oferecido de forma integrada ao ensino médio; Curso Técnico em Manutenção e Suporte em Informática, de forma integrada ao ensino médio na modalidade Educação de Jovens e Adultos; Curso Técnico em Segurança do Trabalho, de forma concomitante e subsequente ao ensino médio; Curso de Graduação em Licenciatura em Química e Curso de Pós-graduação em Educação Física Escolar.

\footnotetext{
$3 \mathrm{Na}$ estrutura curricular dos institutos federais, a expressão “integrado ao ensino médio" refere-se ao formato em que o aluno cumpre a carga horária da parte técnica do curso e todas as disciplinas propedêuticas do ensino médio na própria instituição. Já a expressão "concomitante/subsequente ao ensino médio" diz respeito ao formato em que o estudante cumpre no instituto apenas a parte técnica do curso, devendo estar cursando ou já ter cursado o ensino médio em outra instituição de ensino.
} 
O projeto de resgate da memória institucional desse estabelecimento de ensino possui três objetivos fundamentais: o de manter viva a historicidade do Campus, de modo que essa narrativa seja preservada do apagamento, a fim de que as gerações futuras de alunos, servidores, funcionários terceirizados e todos os que de algum modo se relacionam com esse espaço de produção de conhecimento possam acessar a sua trajetória de existência e as evidências de sua relevância. Pretende-se, também, solidificar os vínculos de pertencimento dos sujeitos que atualmente participam da dinâmica do Campus pela via do reconhecimento mais detido da importância que ele teve na trajetória pessoal, acadêmica e profissional de cada um, bem como das contribuições que esses mesmos sujeitos também deram para a instituição.

Por fim, objetiva-se, ainda, fortalecer a capacidade de produção de narrativa e de investigação memorialística tanto dos estudantes que fazem parte do projeto quanto de todos os indivíduos que contribuirão direta ou indiretamente com a reunião das peças que comporão o acervo. Como ganho indireto, acreditamos que o projeto permitirá à instituição a formulação de uma autocrítica de seu funcionamento, a partir do reconhecimento de lacunas, equívocos e metas ainda não atingidas, reveladas por esse processo de esquadrinhamento de seu histórico.

Esse texto a partir daqui estará dividido em três partes: na primeira, apresentaremos mais detalhadamente o projeto de pesquisa Criação do acervo digital de história e memória do IFRJ Campus Duque de Caxias; na segunda, descreveremos brevemente os momentos mais decisivos da trajetória de existência do IFRJ CDUC, suas realizações e avanços; e, por fim, faremos uma discussão acerca das diversas vozes que farão parte de nossa escavação memorialística na reconstituição do percurso de funcionamento da instituição e de que maneira essa costura polifônica e multiperspectivista contribui para um olhar mais diversificado para a pesquisa e seu objeto.

\section{Estruturação do projeto e alcances iniciais}

O Acervo digital de história e memória do IFRJ Campus Duque de Caxias será hospedado em um ambiente virtual do próprio site institucional do IFRJ e seu planejamento está compartimentado nas seguintes seções, que serão apresentadas como ícones em um menu digital da página inicial:

1. História do Campus - o link deste compartimento direcionará para uma linha do tempo interativa, em que cada ano será configurado como um hiperlink que encaminhará para uma pasta em que estarão depositados vídeos, fotografias, documentos e textos através dos quais sejam relatados os acontecimentos relevantes do referido ano, como eventos acadêmicos, atividades de extensão, torneios esportivos, formaturas das turmas concluintes, gincanas, círculos de leituras e outros acontecimentos de realce.

2. Depoimentos - neste espaço, serão agrupados depoimentos em vídeo que estão sendo recolhidos de pessoas que fizeram parte da história do Campus e manifestam para com a instituição algum papel de proeminência ou vínculo de afetividade, gratidão ou pertencimento. Estão sendo reunidos relatos de personalidades como o diretor-geral do 
CEFET Química, que liderava a instituição de ensino à época em que a Unidade Avançada de Duque de Caxias foi construída e inaugurada (e que com a transformação para IFRJ foi convertido em primeiro reitor da instituição); a primeira diretora da Unidade Duque de Caxias, convertida posteriormente em primeira diretora geral do Campus Duque de Caxias; os primeiros diretores de apoio, os primeiros ocupantes das funções de coordenação e chefia de setores; os alunos pioneiros das primeiras turmas a funcionar no Campus, de cada um dos cursos; os funcionários terceirizados com atuação no espaço desde os primórdios de seu funcionamento; docentes das primeiras levas de professores que lá entraram em exercício e moradores das proximidades do Campus que lá residem há vários anos e que acompanharam de perto sua construção e consolidação.

3. Genealogia das funções gestoras - nessa subdivisão do acervo, será montada uma espécie de "árvore genealógica" interativa cujas ramificações trarão os nomes, fotos e uma minibiografia profissional e acadêmica de cada uma das pessoas que ocuparam cargos de direção, chefia e assessoramento no IFRJ CDUC, como os diretores gerais e de apoio, coordenadores de cursos, chefes de setores, como a Coordenação Técnico-Pedagógica, Biblioteca, Coordenação de Turno e os Coordenadores de Cursos.

4. Histórico do movimento estudantil - esta repartição do acervo trará documentos, fotos, vídeos e outros registros que descrevam a trajetória de atuação do movimento estudantil do Campus, desde a primeira chapa do Grêmio Estudantil Carlos Augusto de Carvalho Mendes (nome escolhido em homenagem ao primeiro professor de Química Geral do Campus e um dos primeiros docentes a ministrar aulas naquele espaço) e do Diretório acadêmico Marie Curie (assim batizado pelos alunos do curso de Licenciatura em Química como uma celebração à reconhecida física e cientista polonesa). Dentre outras informações, nessa parte constará uma mini biografia de todos os alunos que integraram as diferentes chapas de liderança dos dois núcleos do movimento estudantil ao longo dos anos de funcionamento do Campus.

Além das segmentações mencionadas, pretendemos, futuramente, construir um espaço virtual no acervo especificamente destinado ao que estamos chamando de "pré-história do Campus", que seria uma historiografia da região em que a instituição se situa, o bairro de Vila Sarapuí e suas adjacências. Para o alcance desse levantamento, a coordenadora do projeto vem investindo em uma parceria com uma instituição municipal, o Museu Vivo do São Bento ${ }^{4}$, em funcionamento em um bairro próximo ao do IFRJ CDUC e que congrega um grupo de estudiosos cujas investigações se voltam para a história da Baixada Fluminense e do Município de Duque de Caxias em especial. No museu é oferecido, inclusive, um curso permanente de extensão, com conteúdo detalhado sobre a história do município de Duque de Caxias, desde a época do Brasil Colônia até os dias atuais.

4 A propósito do Museu Vivo do São Bento, é possível encontrar informações no site oficial. Disponível em: $<$ https://www.museuvivodosaobento.com.br/>. 
Embora o projeto se encontre hoje em fase bastante inicial e embrionária, a pesquisa já realizou alguns avanços, como o levantamento de fotos e vídeos de diferentes eventos ocorridos no local desde seu primeiro ano de atuação, fotos e vídeos do terreno em que ele se localiza anteriormente à construção do prédio e imagens da construção do prédio, cerimônia de inauguração e primeiras atividades. Também já estamos agrupando os primeiros depoimentos das personalidades que integram o itinerário da instituição e, através de uma parceria com o Campus Engenheiro Paulo de Frontin do IFRJ, em que é oferecido um curso de ensino técnico integrado ao ensino médio em Informática para Internet, do qual um dos alunos é voluntário do projeto, já está sendo desenhado o design e layout do ambiente virtual do acervo e pensadas as formas como os conteúdos serão distribuídos.

Paralelamente às atividades de caráter pragmático da pesquisa, como a congregação de imagens, textos, documentos, vídeos e relatos que figurarão no acervo, elaboração de imagem de capa com identidade visual padronizada para os vídeos com os depoimentos que também integrarão o memorial do campus, os estudantes envolvidos no projeto também vêm realizando, sob supervisão e acompanhamento da orientadora, leituras de textos acadêmicos relacionados aos estudos sobre memória, memória social e memória institucional, a fim de construírem alicerces conceituais e teóricos para as atividades práticas que desempenham e compreensão mais amplificada dos objetivos da pesquisa e sua fundamentação terminológica.

Passamos, então, à descrição dos momentos decisivos da existência do IFRJ CDUC, suas contribuições à comunidade, as ações pedagógica e culturalmente potentes que lá são executadas e as metamorfoses pelas quais o Campus vem passando desde sua gênese.

\section{Breve síntese do percurso do campus - avanços, rupturas, transformações}

A fim de contextualizar o impacto das ações de ensino, pesquisa e extensão realizadas pelo IFRJ Campus Duque de Caxias para a região em que ele se localiza, e, consequentemente, ressaltar a pertinência de fixarmos essas ações no tempo e na lembrança, através da preservação e acessibilização de seus registros, compete-nos fazer uma breve síntese a respeito da carência que a localidade possui de instituições de ensino públicas e de qualidade que promovam educação técnica e profissionalizante em diferentes níveis de ensino.

No artigo A luta pela educação na Baixada Fluminense-RJ: o contexto de expansão do Ensino Superior (SOUZA e SOUZA, 2018), os autores analisam um recorte do processo histórico de consolidação dos municípios que compõem a região e detalham algumas dinâmicas que fazem com que boa parte de seu território seja marcado por desigualdades sociais diversificadas, abandono do poder público em diferentes esferas, variadas manifestações da violência urbana, precariedade dos sistemas educacionais e de saúde, amplo espectro de desemprego e subemprego e uma população maioritariamente carente de bens culturais, serviços e escolarização eficiente. No mesmo texto, os pesquisadores defendem que uma das iniciativas mais potencialmente transfiguradoras da região foi a inauguração de um Campus da Universidade Federal Rural do Rio de Janeiro no município de Nova Iguaçu, importante cidade desse núcleo geoespacial. 
$\mathrm{Na}$ esteira do que defendem os autores do estudo, consideramos que, no caso do município de Duque de Caxias, entre as mais notórias medidas de transformação social da região pela via da educação estão as implantações dos campi da Universidade Federal do Rio de Janeiro, em Xerém, no quarto distrito da cidade; do colégio Pedro II (instituição de ensino, também integrante da Rede Federal de Educação Profissional, Científica e Tecnológica), no bairro do Centenário, próximo ao centro do município; e do Instituto Federal do Rio de Janeiro, no bairro de Vila Sarapuí, cuja população é predominantemente de baixa renda e parca escolaridade.

A educação básica de ensino médio, profissional, técnica/tecnológica e de ensino superior em nível de graduação e pós-graduação provida pelo IFRJ CDUC a estudantes de Duque de Caxias e outras cidades adjacentes é um nítido diferencial pragmático e simbólico para o local, pois permite ascensão socioeconômica aos estudantes que concluem os cursos técnicos e adentram o mercado de trabalho na condição de mão de obra especializada, e, portanto, melhor remunerada, além de oferecer amplitudes de horizontes culturais, artísticos, científicos, uma vez que possibilita uma educação emancipadora e lhes faculta oportunidades de participação em projetos de pesquisa, atividade de extensão, eventos culturais e artísticos, visitas técnicas a empresas e a instituições culturais, dentre outras ações cujo detalhamento da trajetória da instituição desvela e evidencia.

O Campus foi inaugurado no segundo semestre de 2006 e dentre os momentos de maior relevância de seu roteiro de funcionamento estão os anos de implantação de cada um dos cursos que lá funcionam. O curso técnico em Polímeros (posteriormente rebatizado de curso técnico em Plásticos) foi o primeiro a funcionar no espaço e sua primeira turma iniciou seus estudos no primeiro semestre de 2007, na modalidade concomitante/subsequente ao ensino médio. No primeiro semestre de 2008, instaura-se a primeira turma deste mesmo curso na modalidade integrada ao ensino médio, com duração de sete semestres letivos, e o curso técnico em Segurança do Trabalho, na versão concomitante/ subsequente ao ensino médio, com duração de três semestres letivos.

No mesmo ano, é implantado, também, o curso técnico em Manutenção e Suporte em Informática, integrado ao ensino médio, na modalidade Educação de Jovens e Adultos. Merece destaque o fato de que esse curso integra uma determinação mais ampla proposta em 2005 pelo Ministério da Educação, que foi a criação do Programa de Integração da Educação Profissional ao Ensino Médio na Modalidade Educação de Jovens e Adultos - PROEJA, instituído através do Decreto no. 5.478, de 24 de junho de 2005, e ampliado em sua abrangência pelo Decreto $n^{\circ} .5 .840$, de 13 de julho de 2006, com o objetivo de ofertar educação técnica e profissionalizante aos jovens e adultos com defasagem no seu processo de escolarização. Durante esses anos de funcionamento do PROEJA no IFRJ, muitos estudantes da EJA têm conseguido preencher suas lacunas educacionais e adquirir a formação técnica, o que para $o$ universo do público assistido pelo curso é um emblemático divisor de águas.

Ainda em 2008, o Campus avança para uma etapa decisiva, que foi sua inserção no programa institucional do então CEFET Química de bolsas de iniciação científica. Começam a ser realizados os primeiros projetos de pesquisa com a participação de alunos bolsistas PIBIC Jr. Essa possibilidade de estudantes do ensino médio receberem bolsas para atuar em pesquisas coordenadas pelos professores é absolutamente determinante no roteiro de vida dos alunos que 
são contemplados com essa oportunidade. De 2008 aos dias de hoje, foram realizadas inúmeras pesquisas no Campus das quais participaram bolsistas, que puderam aprimorar de modo muito aprofundado e satisfatório suas competências para a investigação científica.

No ano de 2009, inaugura-se o Curso Técnico em Petróleo e Gás, nas variações integrado ao ensino médio e concomitante/subsequente ao ensino médio. Já 2011 foi o ano de implementação do Curso Técnico Integrado em Química, com duração de oito semestres, que vem formando profissionais atuantes em diversificadas ramificações da indústria e outros eixos do mercado de trabalho. Nosso levantamento do histórico de egressos do Campus atesta que muitos dos estudantes desse e dos demais cursos médio-técnicos do Campus adentram boas universidades e seguem carreiras relacionadas ao âmbito da Química e seus derivados, contudo, são muitos os que optam por outras formações acadêmicas na esfera do ensino superior e frequentam os mais diversos cursos de graduação e seguem no exercício de múltiplas e distintas profissões, o que indica um certo caráter plural da educação fomentada pelo IFRJ, que, embora seja prioritariamente voltada para a vida profissional tecnicista, também se direciona para a diversidade de escolhas e variadas formas de realização pessoal e profissional.

Em 2012, começa a funcionar no Campus o Núcleo de Estudos Afro-brasileiros e Indígenas - NEABI e o Núcleo de Apoio às Pessoas com Necessidades Específicas - NAPNE. O NEABI vem promovendo atividades bastante interessantes de pesquisa e extensão em torno da história, linguagem, arte, identidade, religiosidade, culinária e aspectos culturais diversificados dos povos africanos e indígenas que contribuíram para a consolidação da matriz cultural e identitária brasileira.

Nesse período de funcionamento do NEABI, foram ofertadas inúmeras palestras, oficinas, minicursos, exposições e atividades artísticas voltadas para essas questões, além de consultoria pedagógica prestada aos professores com relação ao cumprimento das Leis $\mathrm{n}^{\circ} 10.639$ e $\mathrm{n}^{\circ} 11.645$, que estabelecem a exigência do ensino de história e cultura africana, afro-brasileira e indígena na educação básica. A equipe de servidores e alunos integrantes do NAPNE, por sua vez, vem realizando ações de conscientização em torno da educação especial e inclusiva, através de cursos, palestras e outras atividades acadêmicas e criando mecanismos de acessibilidade aos estudantes portadores de necessidades específicas, a fim de lhes garantir equidade e êxito no processo de aprendizagem.

Em 2015, é fundado no Campus o Núcleo de Gênero e Diversidade - NUGED, grupo de estudos, pesquisas e ações voltadas para o debate dos temas de gênero, sexualidade e diversidade, a fim de colaborar com o combate ao machismo, à homofobia e toda e qualquer discriminação vinculada à identidade de gênero e à orientação sexual, para, assim, contribuir com a educação cidadã e humanística, voltada para a construção de um mundo mais justo e igualitário.

Dentre os momentos mais importantes da história e memória do IFRJ CDUC estão as realizações de seus eventos de extensão, em especial, as duas principais semanas acadêmicas integrantes da programação permanente da instituição: a Semana Científico-Tecnológica - SEMACIT, cuja primeira edição ocorreu em 2008, e atualmente está em sua décima edição, realizada, no ano de 2020, excepcionalmente, de forma remota, através de plataformas virtuais, em função da pandemia de Covid-19, que assolou o Brasil e obrigou a suspensão de atividades de ensino presencial. Essa 
semana acadêmica reúne palestras, minicursos, oficinas, mesas-redondas e projetos discentes, predominantemente voltados para as relações entre ciência, tecnologia e sociedade. Paralelamente à SEMACIT, ocorre também a Jornada Científica, em que são apresentados sob a forma de comunicações os projetos de pesquisa de que participam os alunos dos diferentes níveis de ensino do Campus e, recentemente, foi incorporada a essa rotina acadêmica, também de forma simultânea à SEMACIT, a Jornada de Extensão, em que são apresentados os projetos extensionistas coordenados pelos professores e dos quais os estudantes também fazem parte.

A outra semana acadêmica a funcionar de modo sistemático no estabelecimento de ensino é a Semana de Arte e Cultura - SEMAC, em que são promovidas ações culturais, musicais, esportivas e artísticas, além de uma gincana, que agrega e mobiliza a maior parte dos alunos e fomenta o compromisso deles com tarefas de natureza social, como arrecadação de alimentos para instituições de caridade ou famílias necessitadas e arrecadação de óleo de cozinha usado, para reaproveitamento. A SEMAC confirma o pluralismo pedagógico que os docentes do IFRJ pretendem desenvolver e praticar e possibilita forte envolvimento dos alunos com a cultura, os esportes, o lazer e a descontração, que também integram o processo formativo da educação escolar.

Outros eventos que compõem a trajetória extensionista do Campus são a Semana da Diversidade, composta por palestras, oficinas, debates, exposições e atividades culturais em torno dos temas ligados ao NAPNE, ao NEABI e ao NUGED. A Festa Junina Arraiá Trem Bão, realizada anualmente, também incorpora a programação cultural do Campus e reúne servidores, estudantes e comunidade externa em momentos de cultura e entretenimento, repletos de comidas típicas, dança de quadrilha e brincadeiras.

Além desses eventos, ocorrem no Campus outros mais espaçados, como as olimpíadas escolares, torneios esportivos, cursos de extensão, apresentações musicais e teatrais, atividades de acolhimento aos alunos recém-chegados a cada início de semestre. Em 2017, ocorreu um evento comemorativo dos dez anos de existência do Campus , que se caracterizou por um dia repleto de atividades, como mesas redondas, exposição e a partida de um gigantesco bolo comemorativo.

Todos esses momentos decisivos da história e memória do Campus Duque de Caxias do Instituto Federal do Rio de Janeiro serão registradas em nosso acervo virtual, que poderá ser visitado e amplamente divulgado para toda a comunidade acadêmica do Campus, bem como para o público diverso que deseje conhecer o percurso de existência e realizações desta instituição, que se revela importante na vida dos que dela fazem ou fizeram parte.

\section{As múltiplas vozes que se encontram ou sobre a necessidade de tecer narrativas}

No ensaio O narrador, o filósofo Walter Benjamim, da Escola de Frankfurt, chama a atenção para um processo de enfraquecimento da capacidade humana de produzir narrativas. Para o pensador da teoria crítica, a consolidação do sistema capitalista com seu modo de produção industrializado e seu ethos individualista, ancorado na família nuclear burguesa e na subjetividade moderna levada às últimas consequências, debilitou a noção de experiência coletiva e de 
pertencimento dos sujeitos aos grupos sociais de que fazem parte. Consequentemente, arrefeceuse a capacidade humana de contar histórias, compartilhar experiências e transmitir ensinamentos, conselhos e exemplaridades. Afiliando-nos à preocupação benjaminiana em torno dos prejuízos suscitados por esses processos de ensimesmamento dos indivíduos e de esmorecimento dos laços coletivos e sociais, julgamos pertinente promover iniciativas que possibilitem aos sujeitos construírem relatos de experiências comuns e compartilhadas, que evidenciem o caráter gregário e interdependente da espécie humana e a potência da solidariedade, da empatia e dos vínculos sociais e coletivos dos indivíduos uns para com os outros.

Outro pensador com o qual estabelecemos diálogo é o teórico russo Mikhail Bakhtin, que, em Problemas da poética de Dostoiévski, concebe o conceito de polifonia como sendo uma espécie de orquestra discursiva em que se concatenam e interseccionam múltiplas vozes que emergem e se manifestam na estrutura da narrativa. Ao analisar a obra do importante autor de Crime e castigo, o estudioso desenvolve a ideia de que a prosa desse escritor é profícua e produtiva justamente porque congrega em diversificadas camadas as múltiplas vozes de personagens representativos dos mais diversificados papéis sociais e os variados pontos de vista sobre os fenômenos que se desenrolam na obra.

Tomando de empréstimo o conceito bakhitiniano, podemos considerar como investida polifônica todo texto ou discurso no qual seja possível identificar esse tom orquestral em que diferentes perspectivas se integram na construção de narratividade e produção de saber. No caso do acervo de memória do IFRJ Campus Duque de Caxias, cuja arquitetura está no cerne de nossas preocupações, o caráter polifônico se materializa em diferentes etapas do processo: a começar pelos repertórios de vivência institucional da pesquisadora que coordena o projeto, docente no Campus desde agosto de 2008, passando pelo olhar dos estudantes que atuam diretamente na pesquisa, que trazem a visão discente a respeito do funcionamento da instituição, e se amplia para os múltiplos ângulos a partir dos quais discorrem os diversos narradores que aceitaram produzir e ceder seus relatos para a seção de depoimentos em vídeo do espaço virtual de memória.

Observamos que os depoimentos coletados para o acervo perpassam narrativas de diversificados atores que estabeleceram com a instituição vínculos heterogêneos, como de gestores (como o primeiro reitor do IFRJ, a primeira diretora geral do IFRJ CDUC, os primeiros diretores de apoio, os coordenadores dos cursos e de setores), de estudantes dos diferentes níveis de ensino que são ofertados no Campus (de ensino médio-técnico, graduação e pós-graduação), de professores, de funcionários terceirizados (de limpeza, segurança e manutenção) e da comunidade externa (como pais de alunos, moradores da localidade). A costura dessas múltiplas percepções delineia um mosaico multiprismático e insere dialeticamente as trajetórias dos indivíduos dentro da narrativa institucional, ao evidenciar a relevância de cada sujeito no percurso do Campus, e insere a história da instituição na vida particular de cada narrador depoente, ao avultar para esses mesmos indivíduos as contribuições do IFRJ para seus trajetos pessoais, profissionais, acadêmicos e afetivos.

Ao reconstruir esses extratos de narrativa, reuni-los e disponibilizá-los em um único espaço, o projeto confirma a premissa de Maurice Halbwachs de que a memória é uma instância que se materializa 
de forma coletiva, mesmo quando enunciada por um sujeito particularizado. Fazemos coro com as palavras do teórico, para quem "cada memória individual é um ponto de vista sobre a memória coletiva, que este ponto de vista muda segundo o lugar que ali ocupo e que este mesmo lugar muda segundo as relações que mantenho com outros ambientes." (HALBWACHS, 2003, p. 69).

Defendemos, ainda, que a narrativa, tal como corporificada nos depoimentos dos participantes de nossa pesquisa, tem a função de colaborar na construção dinâmica da identidade institucional, mas, também favorece a constituição identitária dos próprios indivíduos que depõem; uma vez que todos somos em parte resultado das experiências que vivenciamos, da formação escolar que tivemos, das sociabilidades que construímos nos espaços que frequentamos, recuperar fragmentos desses itinerários significa reconstruir quem somos, revisitar nossos trajetos e realinhar anseios, metas, desejos, enfim, nos reconhecer.

É importante ressaltar aqui a pertinência dessa tessitura de relatos na consolidação da noção de memória institucional e sua vinculação com o exercício da cidadania. A esse respeito, Icléia Thiesen salienta, em sua pesquisa de doutorado desenvolvida em torno do conceito de memória institucional, a respeito da combinação entre esse elemento e a cidadania e participação social dos indivíduos. A professora afirma que:

\footnotetext{
Para compreendermos as relações entre memória e instituição é necessário uma articulação com a noção de sociedade/socialização, vista aqui como um processo que indica o conjunto das experiências que formam/conformam a identidade política e social dos indivíduos, bem como a imagem que têm de si mesmos e do outro, em suas relações com as instituições existentes na sociedade. As relações entre indivíduos e instituições são de fundamental importância para o processo de formação/aprendizagem social e política que conduz as ações de cidadania. (THIESEN, 1997, p. 32).
}

Ao fortalecer a premissa de que as instituições de ensino devem ter como horizonte a instrumentalização dos sujeitos para o exercício pleno e autônomo da cidadania e da vida em sociedade, a trama memorialística, que aqui se propõe, colabora não somente com o campo dos estudos de memória, como também com o universo educacional, encarado por nós como um processo inevitavelmente coletivo e plural, que será sempre mais eficiente e produtivo quanto mais amplo e democrático for o direito à voz e participação dos personagens que interagem na dinâmica escolar e acadêmica das instituições de ensino. Nesse sentido, o projeto de pesquisa aqui exposto tem como tarefa, também, contribuir para a proposta de uma educação cidadã, que revitalize a noção de vida em sociedade como eterna construção social de narrativas comuns e experiências compartilhadas.

\section{Considerações finais}

Embora o projeto de criação do acervo digital de história e memória do IFRJ Campus Duque de Caxias esteja em sua fase preambular, acreditamos que as conquistas até aqui realizadas têm sido significativas, especialmente na rotina da coordenadora da pesquisa e dos estudantes que dela participam. As leituras teóricas efetuadas pelos integrantes do projeto e as 
discussões delas derivadas trazem aprendizados profusos em torno dos temas definidores da iniciativa. As atividades como um todo auxiliam os estudantes na internalização das premissas, critérios e metodologias que norteiam a dinâmica da pesquisa acadêmica, o que se traduz como um expressivo diferencial para os jovens alunos de ensino médio.

O que se vem construindo ao longo do projeto é um conjunto de iniciativas que já resultaram em alguns registros imagéticos, documentais e textuais que capturam e evidenciam o histórico de funcionamento de uma instituição de ensino possuidora de importância educacional e sociocultural na região em que se localiza.

A tessitura memorialística tem sido construída de maneira coletiva, a partir de múltiplos olhares para a trajetória institucional, envolvendo diferentes participantes desse percurso, de forma interativa e dialógica, de modo a favorecer a produção de narrativas que integram os indivíduos ao grupo social pela lógica de pertencimento e contribuições mútuas. Com a conclusão da pesquisa e finalização do espaço virtual de memórias, se espera contribuir de forma prática para o campo dos estudos da memória social e da memória institucional pela materialização dos conceitos mobilizados nessas áreas na forma de um acervo digital amplamente acessível para toda a comunidade.

\section{Referências}

BAKHTIN, Mikhail. Problemas da Poética de Dostoiévski. 3. ed. Traduzido por Paulo Bezerra. Rio de Janeiro: Forense Universitária, 2002.

BEnJAmin, Walter. Magia e Técnica, Arte e Política. São Paulo: Brasiliense, 1985.

BERGSON, Henri. Matéria e memória: ensaio sobre a relação do corpo com o espírito. $3^{\mathrm{a}}$ Ed. São Paulo: Martins Fontes, 2006.

DODEBEI, V. L. D. L. de M. Informação, memória, conhecimento: convergência de campos conceituais. In: ENCONTRO NACIONAL DE PESQUISA EM CIÊNCIA DA INFORMAÇÃO, 10., 2010. ANAIS... Rio de Janeiro: UFRJ, 2010.

HALBWACHS, Maurice. A memória coletiva. São Paulo: Centauro, 2003.

LE GOFF, Jacques. História e Memória. Campinas: Unicamp, 1990.

MOLINA, Letícia G. e VALENTIM Lígia P. Memória organizacional, memória corporativa e memória institucional: discussões conceituais e terminológicas. In: Revista EDICIC, v.1, n.1, p. 262-276, ene/mar. 2011. Disponível em: <https://repositorio.unesp.br/bitstream/ handle/11449/115215/ISSN2236-5753-2011-01-n.1-262-276.pdf>. Acesso em: 15 dez. 2020. 
THIESEN, Icléia. Memória institucional: a construção conceitual numa abordagem teórico-metodológica. Tese (Doutorado em Ciência da Informação) - Faculdade de Comunicação, Universidade Federal do Rio de Janeiro. Rio de Janeiro: UFRJ, 1997.

SANTOS, M. S. dos. Memória coletiva e teoria social. São Paulo: Annablume, 2003.

SOUZA, Renan Arjona e SOUZA, Nádia Maria Pereira de. A luta pela educação na Baixada Fluminense-RJ: o contexto de expansão do Ensino Superior. In: COLÓQUIO - Revista do Desenvolvimento Regional - Faccat - Taquara/RS - v. 15, n. 1, jan./jun. 2018. 
